\title{
Özofagusta geç dönemde saptanarak endoskopik olarak çıkarılan yabancı cisim
}

\author{
Endoscopic removal of esophageal foreign body (chicken bone)
}

Bilal ERGÜL, Levent FILIK, Zeynal DOĞAN, Ibrahim BIYIKOĞLU

Ankara Eğitim ve Araștırma Hastanesi, Gastronenteroloji Kliniği, Ankara

Erişkinlerde özofagusa yabancı cisim takılması sık karşılașllan bir durum değildir. Vakalar çoğunlukla ilk 24 saatte tanı alır. Tavuk kemiği yuttuktan sonra özofagus orta kesime impakte olan ve 10 gün sonra geç dönemde tanı alan, endoskop yardımı ile başarılı bir şekilde çıkanılan bir vakayı sunuyoruz.

Anahtar kelimeler: Özofagusta yabancı cisim, endoskopik çıkarma, gıda takılması

\section{GİRISS}

Yabancı cisim yutulması, gastrointestinal sistem kanamasından sonra en sık karşılaşılan endoskopik acildir (1). Özellikle 6 ay- 6 yaş çocukluk çağında daha sık rastlanmakla birlikte, erişkin yaş grubunda da karşılaşılabilen ciddi morbidite ve mortaliteye neden olabilen bir sorundur (2). Erişkinlerde zeka geriliği veya psikiyatrik hastalık öyküsü olanlarda, alkol intoksikasyonu olanlarda ve dental protezi olanlarda daha sıklıkla karşımıza çıkmaktadır. ABD'de her yıl yaklaşık 1500 kişi yabancı cisim yutulmasına bağlı komplikasyonlar nedeniyle hayatını kaybetmektedir (3).

Gastrointestinal sistemdeki en dar bölge özofagus olması nedeniyle yutulan yabanci cisimler sıklıkla burada takılmaktadir. Gastrointestinal sistemdeki yabancı cisimlerin \%28-68'i özofagusta saptanmaktadır. Takılmalar sıklıkla, fizyolojik daralma bölgeleri olan krikofaringeal kas seviyesi, aort ve sol ana bronş ile çaprazlaşma bölgeleri ve özofagusun diyafragmayı geçtiği yerde olmaktadır (4).

Erişkin yaş grubunda hastalarda çoğunlukla ağrılı yutma veya takılma hissi şikayeti olur ve vakaların büyük bir kısmı ilk 12 saat içinde başvurur. Biz burada, yutarken takılma hissi olan ve göğsünde hafif ağrı şikayeti ile başvuran ve öyküsünden 10 gün önce tavuk yerken boğazına kaçtığı öğrenilen, geç dönemde tanı konulan bir vakayı sunuyoruz.

\section{OLGU}

Altmış üç yaşında erkek hasta Gastroenteroloji polikliniğine göğsünda hafif bir ağrı hissi ve yutarken zorlanma, takılma hissi nedeniyle başvurdu. Bilinen kronik hastalık öyküsü yoktu. Son birkaç gün içinde ilaç kullanımı veya kostik bir ajana
Lodging of foreign bodies in the esophagus is not frequent in adults. The cases are often diagnosed within the first 24 hours. We present herein a case who had swallowed a chicken bone 10 days before that had become embedded in the middle segment of the esophagus. Successful removal of the bone was achieved with the aid of an endoscope.

Key words: Esophageal foreign body, endoscopic removal, stucking food

maruziyet öyküsü yoktu. Öyüsü daha detaylı sorgulandığında, 10 gün önce tavuk yediğini, yemek esnasında boğazına birşey kaçtığını hissettiğini belirtti. Lokal anestezi eşliğinde yapılan endoskopide özofagus orta kesimde sivri uçları aşağıya bakan "V" şeklinde tavuk kemiği (lades kemiği) izlendi (Resim 1). Dişli yabancı cisim forsepsi ile uç kısmından yakalanarak endoskop ile birlikte çıkarıldı (Resim 2). Özofagusta impakte olduğu bölge tekrar kontrol edildiğinde karşılıklı uçların temas ettiği bölgelerde derin ülserler oluşturduğu görüldü (Resim 3). Perforasyon açısından çekilen akciğer grafisinde mediastende serbest hava izlenmedi, baryumlu özofagografide de baryum kaçağı görülmedi. Hastaya sükralfat ve proton pompa inhibitörü tedavisi başlandı.

\section{TARTISSMA}

Yabanci cisimler, gastrointestinal sistemde herhangi bir bölgede impakte şekilde, perforasyon, obstrüksiyon veya fistülizasyon ile karşımıza çıkabilir. Fizik muayenede obstrüksiyon veya perforasyona bağlı bulgular olabileceği gibi tamamen normal de olabilir. Tanı çoğunlukla hastadan alınan detaylı anamnez ve uygun görüntüleme yöntemi ile konulur. Radyolojik görüntüleme yöntemleri yabancı cismin yerinin tespitinde yararlıdır. Düz grafi ile \%87 oranında yabancı cisim saptanabildiği bildirilmiştir (3). Balık kılçığı, tavuk kemiği, plastik veya cam nesnelerin direk grafi ile tespit edilme şansları daha düşüktür (2).

Üst özofagus sfinkterini geçerek mideye ulaşan yabancı cisimlerin, sindirim sisteminin diğer kısımlarında takılma riski çok düşüktür (2). Özellikle düzgün kenarlı ve küçük nesnelerin, seri x-ray ile gastrointestinal sistemdeki yolculuğu takip edi- 


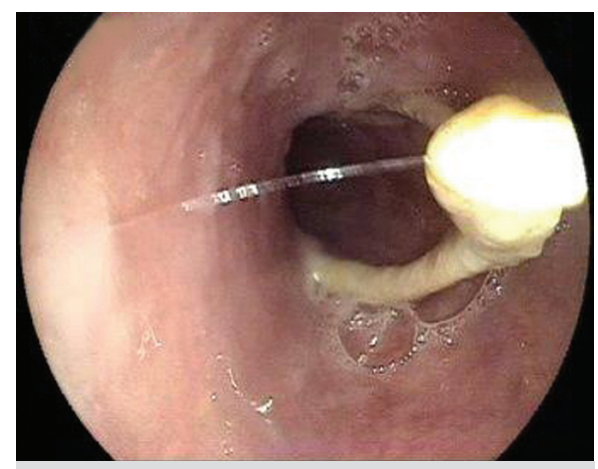

Resim 1. Özofagusta takılı tavuk kemiği.

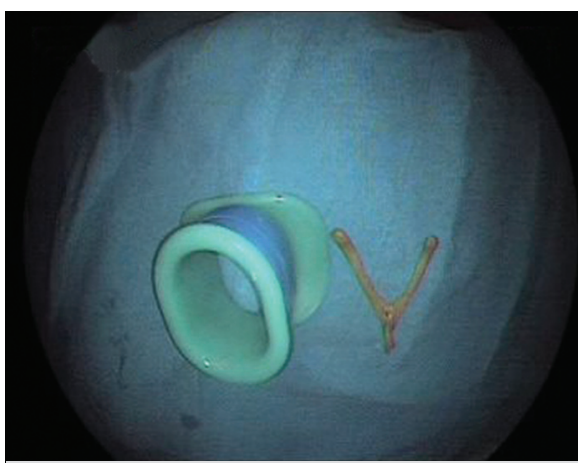

Resim 2. Endoskopik olarak özofagustan çıkarılmış tavuk kemiği.

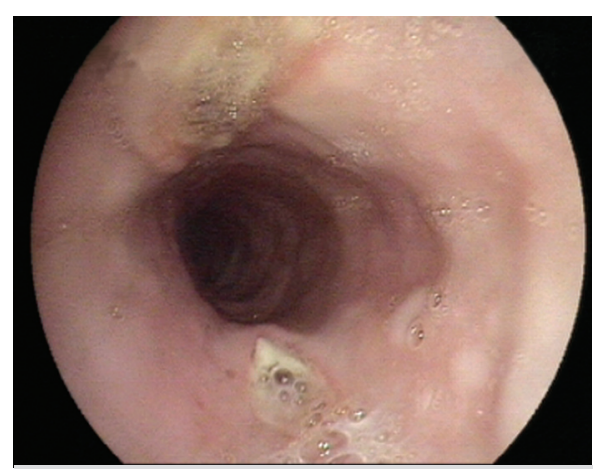

Resim 3. Olgunun tavuk kemiği çıkarıldıktan sonraki kontrol endoskopi görüntüsü. lebilir veya bekle-gör taktiği uygulanabilir. 2 cm'den geniş 6 cm'den uzun nesnelerin pilor kanalından geçmesi çok zor olması nedeniyle çıkarılması tercih edilmektedir Erişkin yaş grubunda daha fazla görülen tavuk kemiği ve balık kılçığı gibi veya diğer sivri nesnelerin komplikasyon riski daha yüksek (\%35) olması nedeniyle endoskopik olarak çıkarılması daha akılcı bir yaklaşımdır (5).

Yabancı cisim yutan hastaların tedavisi hastanın yaşına, klinik durumuna, yutulan cismin büyüklüğü, şekli ve zehirli, koroziv veya keskin olmasına ve saptandığı yere bağlıdır. Weiland ve arkadaşları, yabancı cisim yutan 439 hastanın \%84.5'inde özofagusta tespit etmişlerdir (1). Yabancı cisimlerin özofagusta 24 saatten uzun süre kalmasina izin verilmemelidir (2). 24 saati geçtiğinde terapötik endoskopik girişim süresi artmakta, özofageal ülserasyona yol açarak iyileşme süresi uzamakta, aortaözofageal fistül, pnömotoraks gibi hayatı tehdit eden komplikasyon riski artmaktadır. Fizik muayenede krepitasyon önemli bir bulgudur ve tomografi bu olguların atlanmamasında yer tutar. Bizim vakamızda 8 günlük bir öykü mevcut olup tavuk kemiğinin impakte olmasına bağlı derin ülser saptanmıştır.

Endoskopi hem tanıda hem de yabancı cismin çıkarılmasında oldukça faydalıdır. Keskin veya sivri uçlu cisimlerin çıkarılırken, sivri ucun endoskopun içine alınması, dışarı çıkartılırken oluşabilecek olası perforasyon riskini azaltır. Bazı olgular- da, yabancı cisim çıkartılırken sivri ucun görüntüde kalması için endoskoptan uzakta bırakılarak çekilmesi uygun bir yaklaşım olabilir. Forseps keskin, basket ise künt cisimlerin çıkarılmasında daha başarılıdır (1). Overtube bazı olgularda uygun olabilir. Yabancı cisim çıkarıldıktan sonra malignite, striktür, akalazya, divertikül gibi altta yatan ek patolojinin varlığının aydınlatılması için kontrol endoskopik inceleme yapılmalıdır. Bizim vakamızda dişli yabancı cisim forsepsi ile yabancı cisim çıkarılmış, kontrol endoskopisinde altta yatan organik bir patoloji saptanmamıştır.

1994-2009 yılları arasındaki 177 olgunun analizinde \%75'inin radyoopak, yutulan nesnelerin ise \%71'inin servikal özofagusta olduğu, yutulan şeylerin \%53'ünün metalik \%35'inin ise kemik veya et olduğu saptanmıştır (6). 19901997 yılları arasında özofagusta yabancı cisim saptanan 682 olgunun incelenmesinde, olguların \%68' inin 5 yaşından küçük, \%90' ının ilk 10 saatte başvurduğu, sadece \%3'ünde 24 saatten geç başvuru olduğu, cisimlerin \%87 oranında üst özofagusta olduğu ve en sik metal para (\%77), daha sonra kemiket olduğu (\% 10) saptanmıştır (7).

Sonuç olarak, ağrılı yutma veya boğazında takılma hissi olan tüm hastalarda radyolojik görüntülemesi normal dahi olsa yabancı cisim yutulmasından şüphelenilmeli, mutlaka detaylı öykü sorgulanmalıdır. Endoskopi, hem tanıda hem de cisimin çıkarılmasında etkin ve güvenli bir yöntemdir.

\section{KAYNAKLAR}

1. Weiland ST, Schurr MJ. Conservative management of ingested foreign bodies. J Gastrointest Surg 2002;6:496-500.

2. Eisen GM, Baron TH, Dominitz JA, et al; American Society for Gastrointestinal Endoscopy. Guideline for the management of ingested foreign bodies. Gastrointest Endosc 2002;55:802-6.

3. Ayantunde AA, Oke T. A review of gastrointestinal foreign bodies. Int J Clin Pract 2006;60:735-9.

4. Block B, Schachschal G, Schmidt H. Endoscopy of the upper GI tract: A training manual. Accessed June 15, 2010.
5. Triadafilopoulos G, Saltzman JR, Travis AC. Foreign bodies in the esophagus in adults. UpToDate. Accessed September 13, 2010.

6. Nadir A, Sahin E, Nadir I, et al. Esophageal foreign bodies: 177 cases. Dis Esophagus 2011;24:6-9.

7. Inci I, Özçelik C, Ülkü R, Eren N. Özofagus yabancı cisimleri: 682 olgunun incelenmesi. GKDC Dergisi 1999;7:148-52. 